\title{
Läufer leben länger - wenn sie nicht übertreiben
}

- Bis zu sechs Jahre erlaufen sich Jogger an Lebenszeit, lautet das Ergebnis einer dänischen Langzeitstudie. Allerdings scheint sich eine U-förmige Beziehung zwischen Trainingsdauer und Sterblichkeit abzuzeichnen. Zwar leben Jogger in der Regel länger als Nichtläufer, die besten Aussichten haben aber offenbar Läufer, die höchstens dreimal wöchentlich insgesamt 1-2,4 Stunden in niedrigem bis mittlerem Tempo unterwegs sind.

Um das Mortalitätsrisiko von Joggern zu erfassen, wurden 17589 gesunde Männer und Frauen zwischen 20 und 98 Jahren im Rahmen der Copenhagen City Heart Study untersucht und zu ihren körperlichen Aktivitäten befragt. 1878 Personen waren bekennende Jogger.

Während der bis zu 35-jährigen Beobachtungszeit starben 122 Jogger und 10158 Nichtjogger. Für Läufer errechneten die Autoren altersadaptiert ein um $44 \%$ reduziertes Gesamtmortalitätsrisiko. Nach Berücksichtigung von BMI, Rauchen, Alkohol- konsum etc. ergab sich für joggende Frauen ein um 40\%, für Männer ein um 31\% niedrigeres Sterberisiko als für Nichtläufer.

\section{Langsam, nicht zu lang und nicht zu oft}

Erwähnenswert sind die Subanalysen zum Einfluss von Häufigkeit, Dauer und Intensität der Trainingseinheiten: So senkte schon eine Laufzeit von unter einer Stunde pro Woche das Sterberisiko gegenüber den Nichtläufern um $32 \%$ und von 1-2,4 Stunden um $42 \%$. Doch dann drehte sich die Kurve: Bei Trainingszeiten zwischen 2,5 und 4 Stunden wurden nur noch $21 \%$ gewonnen und bei mehr als vier Stunden nur noch $14 \%$.

Bei der Trainingshäufigkeit ergab sich ein ähnliches Bild: Bis zu dreimal Joggen pro Woche brachte $60 \%$ Risikoreduktion. Für die, die häufiger die Laufschuhe schnürten, errechneten die Autoren sogar ein erhöhtes Sterberisiko von $24 \%$ gegenüber den Lauffaulen. In die gleiche Kerbe schlug

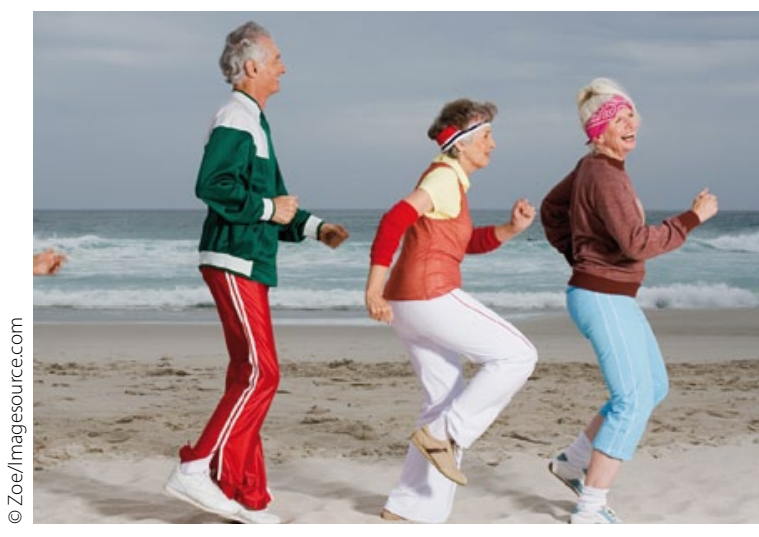

Im gemächlichen Trab kommt man im Leben am Weitesten.

auch das Ergebnis der dritten Subanalyse: Langsam laufen schien den meisten Erfolg zu bringen, denn Jogger dieser Gruppe verringerten ihr Sterberisiko um 63\%. Diejenigen, die in moderatem Tempo unterwegs waren, erreichten immerhin noch $47 \%$, wer aber noch schneller lief, der schnitt letztlich sogar schlechter ab als die Nichtläufer.

ST $=$

Schnohr P et al. American Journal of Epidemiology 2013; online 28. Februar 2013; doi: 10.1093/aje/kws301

\section{Wie gesund muss "Mann" sein?}

Kürzlich wurde in Berlin der erste bundesweite Kongress zum Thema "Männergesundheit" veranstaltet. Von wem, das ließ sich nicht genau eruieren. Aber es soll sich, so wird kolportiert, eine Organisation dahinter verbergen, bei der das weibliche Geschlecht dominiert. Auf dieser Veranstaltung haben sich also zwar nicht nur, aber vorwiegend Frauen über einige Tage sehr intensiv und mit sehr sorgenvoller und leidgeplagter Miene intensiv darüber Gedanken gemacht, wann ein Mann eigentlich gesund ist und wie gesund er eigentlich zu sein hat. Auch diesmal ergab sich als Fazit: wer sich als Mann gesund fühlt, ist eigentlich nur unzureichend untersucht.

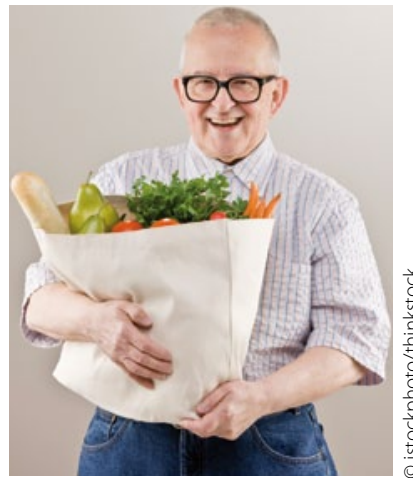

So gesund lebt nicht jeder Mann.
- Das Fehlen von Gesundheit wird von Männern sehr viel seltener bemerkt als dies Frauen lieb und auch bei Frauen der Fall ist.

- Männer misstrauen sehr viel häufiger der weit verbreiteten Auffassung, dass Gesundheit ein Zustand ist, der nichts Gutes verheißt. Kurzum, wenn es um die Gesundheit geht, sind Männer einfach glücklicher und zufriedener, man könnte auch sagen anspruchsloser. Damit sind sie allerdings - Gott sei's geklagt - gegenüber den Marketing-Aktivitäten der Gesundheitswirtschaft immun, also eine sehr schwierige Zielgruppe. Am besten wäre deshalb, man würde alle Männer in Sachen Die Ergebnisse im Einzelnen:

- Männer sind anders gesund als Frauen und dies ist nicht gut so.

- Männer betreiben signifikant weniger Aufwand als Frauen, um sich die Gesundheit bestätigen zu lassen.
Gesundheit entmündigen und sie einer weiblichen Pflegschaft unterstellen. Mit einem solch konsequenten wohlwollenden "Maternalismus" würde sich das Thema "Männergesundheit" eigentlich erübrigen; denn gesund ist, was Frau meint und wünscht.
DR. MED. Peter Stiefelhagen = 